\section{Endoscopic diagnosis of secondary aortoesophageal fistula}

Secondary aortoesophageal fistula (AEF) is a catastrophic complication of endovascular graft placement [1]. The typical symptom of secondary AEF is massive gastrointestinal bleeding with a history of thoracic aortic aneurysm repair [2]. Endoscopy is the most sensitive and specific diagnostic study [3]. Endoscopy should be carefully performed, as it excludes other, more common causes of upper gastrointestinal bleeding, but should be terminated if a fistula is identified. We present an endoscopic finding of secondary AEF.

A 60-year-old woman was diagnosed with a mycotic thoracoabdominal aortic aneurysm and underwent resection of the aneurysm with an in-situ prosthetic interposition graft. Two weeks later, she developed massive hematemesis with hypotension. Emergency esophagoscopy revealed that the graft had eroded into the upper esophagus, with active bleeding ( $\bullet$ Fig. 1). Angiography with endovascular stenting and coil embolization were performed but failed to control the bleeding ( $\bullet$ Fig. 2). The patient died from exsanguinating hemorrhage.

Endoscopy_UCTN_Code_CCL_1AB_2AC_3AG

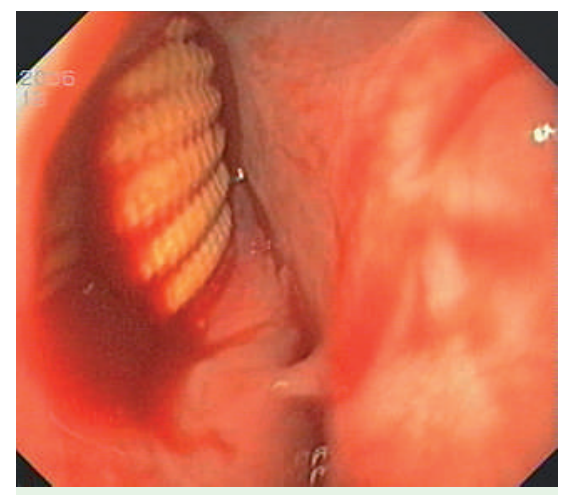

Fig. 1 Endoscopic view showing the Dacron graft in the upper esophagus with bleeding.

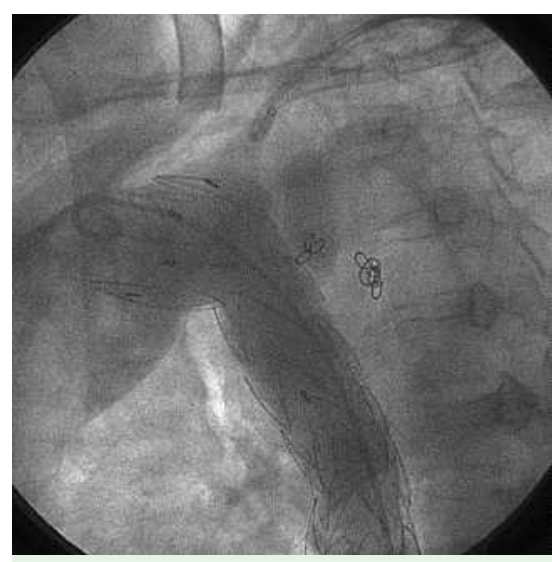

Fig. 2 Aortogram showing the endovascular stent with coil embolization and continuous leakage.
T. Akaraviputh ${ }^{1}$, T. Sriprayoon ${ }^{2}$, V. Prachayakul' ${ }^{2}$, P. Sakiyalak ${ }^{1}$

${ }^{1}$ Department of Surgery, Faculty of Medicine Siriraj Hospital, Mahidol University, Bangkok 10700, Thailand

2 Division of Gastroenterology, Department of Medicine, Faculty of Medicine, Siriraj Hospital, Mahidol University, Bangkok 10700, Thailand

\section{References}

1 Sinar AR, Demaria A, Kataria YP, Thomas FB. Aortic aneurysm eroding the esophagus. Dig Dis Sci 1977; 22: 252 - 254

2 Carter R, Mulder GA, Snyder EN Jr, Brewer LA III. Aortoesophageal fistula. Am J Surg 1978; 136: $26-30$

3 Sosnowik D, Greenberg R, Bank S, Graver LM. Aortoesophageal fistula: early and late endoscopic features. Am J Gastroenterol 1988; 83: 1401 - 1404

Bibliography

DOI $10.1055 / \mathrm{s}-2007-995549$

Endoscopy 2008; 40: E90

(c) Georg Thieme Verlag KG Stuttgart · New York . ISSN 0013-726X

Corresponding author

\section{T. Akaraviputh MD}

Division of Endolaparoscopic Surgery

Department of Surgery

Faculty of Medicine

Siriraj Hospital

Mahidol University

Bangkok 10700

Thailand

Fax: +66-2-412-1370

sitak@mahidol.ac.th 